\title{
THE ENHANCEMENT OF UNDERWATER CULTURAL HERITAGE ASSETS USING AUGMENTED REALITY (AR)
}

\author{
A. Malliri ${ }^{1}$, K. Siountri ${ }^{1,2}$, E. Skondras ${ }^{1}$, D.D. Vergados ${ }^{1 *}$, C.-N. Anagnostopoulos ${ }^{2}$ \\ ${ }^{1}$ M.Sc. Digital Culture, Smart Cities, IoT and Advanced Digital Technologies, Department of Informatics, University of Piraeus, \\ GR-185 34, Piraeus, Greece \\ (mallirhnatas@gmail.com; ksiountri@unipi.gr; skondras@unipi.gr; vergados@unipi.gr) \\ ${ }^{2}$ Cultural Technology and Communication Dpt., University of the Aegean, GR-81 100, Mytilene, Greece \\ (ksiountri@aegean.gr; canag@aegean.gr)
}

Commission II, WGII/9

KEY WORDS: Augmented Reality (AR), Fifth Generation (5G) Networks, Cloud Computing, Maritime Archaeology, Digital Culture

\begin{abstract}
:
The development in the fields of Underwater Cultural Heritage (UCH) management and Maritime Archaeology, yields an interdisciplinary and creative academic framework, such as the Information and Communication Technologies (ICT) sector that has been proved to build intelligent systems and applications. However, the ways to fully make use of these technologies are still being explored, as their potential have not been exploited yet. Underwater archaeological sites, semi (/or fully) submerged settlements, ancient ports and shipwrecks, unlike land sites, are not accessible to public due to their special (sub) marine environment and depth. In this paper, an innovative research idea of using Augmented Reality (AR) for maintaining the memory and the information of underwater archaeological sites, is presented. Although the "artificial" visual documentation cannot replace the authentic values of the underwater tangible heritage, the AR technology can contribute to the protection of the intangible properties and the conquered knowledge of the past of a place. This research work will focus, among other case studies, on the (semi) submerged fortifications and their contiguous contents of the acropolis of Halai in east Lokris, Greece. Hence, along with the climate change that may lead more antiquities covered by water during the following years, the advances in the communication field and the up-coming 5G and cloud technologies will make the idea fully applicable, contributing to the enhancement of the coastal and the underwater archaeological remains.
\end{abstract}

\section{INTRODUCTION}

The development in the fields of Underwater Cultural Heritage Management ( $\mathrm{UCH})$ and Maritime Archaeology yields an interdisciplinary and creative academic framework. The expansion of Information and Communication Technologies (ICTs) has been proved to offer great possibilities in the field of culture by developing new ways of enhancing visitor's experience in sites with cultural interest, changing the way people experience their environment. One of the most promising and popular technologies that provides the user with an integration of digital contents with real images is augmented reality (AR) (Vecchio et al., 2015).

Unlike land sites, semi (/or fully) submerged settlements, ancient ports, shipwrecks and coastal instatements are not accessible to public due to their special (sub) marine environment and depth (Liarokapis et al., 2017). Through the remarkable achievements in digital technologies, including wireless communications and smart devices, the exploitation of AR models is now feasible, in order to provide a better understanding of coastal and underwater cultural heritage assets.

In underwater archaeological sites, the production of immersive AR models is focused on the virtual reconstruction of the archaeological findings. Until nowadays, the dominant trend of the AR implementation in underwater archaeological sites is the production of three-dimensional (3D) models for the purpose of virtual reconstruction of shipwrecks, ancient ports, architectural installations, cargo and so forth, aiming to give digital accessibility to both scholars and visitors (Skarlatos et al., 2016). In the field of coastal archaeological sites, AR remains a challenging task. When it comes to coastal landscapes the difficulty lies in their turbulent character. So, the visualization and the modeling of the cultural traces that being contained within this distinct zone, as a process, are intricating and need a common methodological lingua. A remarkable establishment of an interdisciplinary geo-archaeological survey methodology and lingua of seacoasts is being implemented by the A.Sho.Re project (Yiannouli, 2016). However, the ways to go beyond the today's use of AR are still being explored, as we have not exploited yet the potential of the new technologies in terms of digital content, usability, accuracy and end-user services (Han et al., 2014; Olsson et al., 2012).

Although the "artificial" visual documentation cannot replace the authentic values of the maritime tangible heritage, the AR technology can contribute to the protection of the intangible properties and the conquered knowledge of the past of a place (Siountri et al., 2018).

The main aim of the research idea presented here is to investigate whether a coastal or an underwater archaeological site can be explored and demonstrated within the operating principles of the 
"Smart Cultural Heritage" (SCHaaS) as a service (Siountri et al., 2018). Taking into consideration the concept of the upcoming evolution of the fifth generation (5G) Wireless Communication Networks and the developments in the field of Cloud Computing (CC), Mobile Edge Computing (MEC) or Fog infrastructures, sensors and IoT devices together with services, this paper proposes a system architecture which deals with the innovative idea of using AR for maintaining the memory and the information of semi (/or fully) submerged archaeological sites, which are at risk of being forgotten or passed by due to the peculiarity of their environment.

The considered scheme idea is going to be implemented through one study case: the archaeological site of Halai, in east Locris (Greece) (Coleman et al., 2017). The excavation project of the site is under the direction of the American School of Classical Studies in Athens (ASCSA).

The remainder of the paper is organized as follows: Firstly, current uses of AR technology in the underwater cultural heritage topic are described. Furthermore, the use of AR is studied in the case of the (semi) submerged fortifications of Halai in east Lokris, Greece. Subsequently, the proposed system architecture is described, while the final section concludes our work.

\section{STATE OF THE ART}

\subsection{AR Technology in Underwater Cultural Heritage}

Nowadays, AR technology has raised great attention and interest with several applications (entertainment, education, commerce, art, medicine etc). Although, the research in the field of AR dates back from the 1960s (Kounavis et al., 2012), the debut of smart devises in 2007 enabled high accuracy geolocation featuring components required for AR applications such as cameras, gyroscopes, solid state compasses and accelerometers (Haugstvedt \& Krogstie, 2012).

Augmented Reality, by definition, supplements reality rather than completely replacing it, as it provides a way of presenting physical objects (existing environment) in their surroundings with additional virtual descriptions or graphic content (virtual environment) using video, pictures maps, graphics, sounds, vibration etc. In such way, the computer-generated data is overlying the real-world and the user can see virtual and real objects coexisting in the same space (Noh et al., 2009).

The dominant trend of the AR implementation in archaeological sites is the production of 3D models of monuments in their past situation (virtual reconstruction) aiming to give visitors the third dimension (height, volume etc.), especially to those who do not have special knowledge of archaeology.

An AR application is considered (Vecchio et al., 2015) to manage a) the detection of objects within the scene (either marker-based, markerless or location-based detection), b) overlay the digital content with the real scene and c) the management of huge amount of data with several formats, such as texts, images, video, sounds associated to a specific cultural asset.

In sites with cultural interest, AR can improve visitors' experience with a time navigation (timeline) or with the integration of $3 \mathrm{D}$ models, data and storytelling, tagged to a specific geolocation on the environment. Augmented reality, therefore, becomes an instrument of intersection between history (in its scientific issues of relationship with sources, philological interpretation, critical analysis and presentation) and memory
(Brusaporci et al., 2017), that can increase the audience awareness of the uniqueness of a place (Antonczak et al., 2017).

The use of new technologies and especially the implementation of AR models improves the exploitation of Underwater Cultural Heritage $(\mathrm{UCH})$. The Underwater Cultural Heritage $(\mathrm{UCH})$ according to (Bruno et al., 2017) «is an immeasurable archaeological and historical resource, with extensive and varied assets (sunken cities, ancient shipwrecks, prehistoric submerged landscapes, and sacrificial sites, remains of ancient fishing installations and ports), but it cannot be easily accessible by humans due to a number of limitations imposed by the underwater environment». As a result, it is quite evident that $\mathrm{AR}$ and VR models enhance the accessibility of the UCH and allow any user to live an immersive learning experience with a distinct emotional reaction. (Bruno et al., 2017). It is worth noting that the emersion is in charge of the sensation of being part of the VR/AR environment (Ijsselstein and Riva, 2003). The feeling of the presence is dynamic and decisive when it comes to participate in an interactive experience of a real-world environment.

During the last two decades considerable improvements have been carried out in the UCH field. The 2001 Unesco Convention on the Protection of the Underwater Cultural Heritage has demonstrated remarkable achievements in the field of submerged archaeological sites, by defining the basic principles and recommendations for the protection and in-situ conservation of the submerged archaeological sites. Moreover, the European Commission through the principle of Blue Growth Strategy seems to bring together mainly research institutes and museums with tourism companies, in order to boost an alternative and sustainable way of tourist coastal exploration and development.

In this context, many interdisciplinary and co-operative projects have been (/are) implemented at the scientific forum. The VISAS project (Virtual and augmented exploitation of Submerged Archaeological Sites) develop an integrated package of services for "improving the visitors' experience and enjoyment" (Bruno et al, 2017) of underwater archaeological sites. Through this project users have the unique opportunity to live an immersive exploration of underwater archaeological sites from Italy, Greece and Croatia, which they wouldn't have had the chance to see them before, due to the various limitations imposed by the submerged environment (Bruno et al, 2017). The potential of AR to enhance immediate surroundings through the projection of digital content into users' real environment has been discussed in various research contexts (Han et al., 2013, Hammady et al., 2016). For the tourism industry, an increasing number of scholars recognize the potential of AR for the enhancement of the tourism experience (Leue et al., 2015). For example, in the VISAS project, the AR tool improves the diver tourists' experience in the submerged archaeological site (Bruno et al., 2016).

The innovative project iMARECULTURE (Advanced VR, iMmersive Serious Games and Augmented REality as Tools to Raise Awareness and Access to European Underwater CULTURal heritagE) is focusing to make use both of dry-diving and diving experience. This project aims to raise the European maritime and underwater cultural awareness through immersive technologies, augmented and virtual reality. Especially designed underwater tablets using Augmented Reality will, according to the researchers (Skarlatos et al., 2016), superimpose information about specific finds and architectural designs on the screen of a specially designed underwater tablet. The information will be provided in real time and on user's demand, in order to avoid overloading the diver. 
Taking into consideration the research ideas and proposals of distinct interdisciplinary projects that are implemented in the wider scientific area of the Maritime and Underwater Cultural Heritage, the significance of dry-dive experience of (semi) submerged antiquities in UCH sites has been noticed. Thus, in this paper a research method that allows users to experience the underwater cultural heritage assets of a place, through "smart" and AR technologies, without diving is proposed. Yet, according to (Dieck et al., 2018) the developments in the field of smart glasses and watches extend the opportunities of AR wearable computing technology. With the help of the proposed system architecture, which is analyzed in Section 4, users will be able to receive instant information on unknown underwater surroundings providing a new learning experience by using marker-based or location-based AR applications. Therefore, a primary goal of this research idea is to sustain the coastal tourism of underwater archaeological places, by offering a "Smart Cultural Heritage" experience as a Service (SCHaaS).

\section{THE CASE STUDY OF THE HALAI}

This research work will focus on the (semi) submerged fortifications and their contiguous contents of the acropolis of Halai in east Lokris, Greece.

\subsection{Archaeological-Topographical Description of the place}

Halai, a small ancient town in East or Opountian Locris, is situated "hard by the sea" (Coleman, et al., 1992) on the southeastern shore of the North Euboean Gulf at the east end of the bay known to Strabo (9.4.2) as the Opountian Gulf and called nowadays the Bay of Atalante. The ancient city of Halai was located on the southeastern side of Atalante Bay (Figure 1) and was a fortified harbor-town. The small low hill that later became the acropolis was originally inhabited during the Neolithic period (6000-5300 BC) and then abandoned for about 5000 years. Around $600 \mathrm{BC}$ the hill was once again inhabited as an acropolis of a new city with an area of about $55 \mathrm{~km}$.

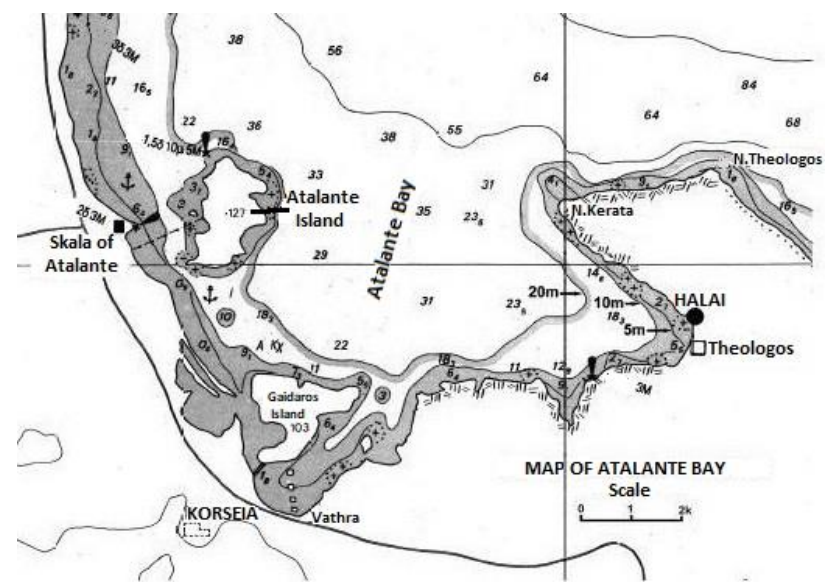

Figure 1. The Bay of Atalante (C) J. Coleman

Prof. John E. Coleman and his team excavated the site of Halai during the «Cornell Halai and East Lokris Project» (CHELP), under the direction of the American School of Classical Studies in Athens (ASCSA) (Coleman et al., 1992, Coleman et al., 2017). CHELP's work began in 1985 with the re-designing of the acropolis remains (Figure 2), while surface surveys were carried out over an area of approximately $185 \mathrm{~km}$, providing a clear picture of the Halai region and its borders. Surface research has provided evidence of the existence of an additional external fortification wall around the Hellenistic Acropolis. This research has been followed, since 1990, by new excavations on the acropolis and a systematic study of the finds. In 1992, CHELP carried out underwater excavations in front of the acropolis in Area G (Figure 3), in collaboration with the Ephorate of Underwater Antiquities of the Hellenic Ministry of Culture and Sports, during which Hellenistic buildings were located (Coleman et al., 1999, O' Neill et al., 1999).

The first excavations of the site were carried out from 1911 to 1935 by Hetty Goldman and Alice Walker (Kosmopoulos) (Goldman, 1940) (Figure 4). These excavations have shown that Halai had a fortified acropolis in classical times which continued to be occupied until Late Roman or Byzantine times and that extensive Neolithic deposits underlay the classical ones (Coleman et al., 1999). Two hundred and eighty tombs of Archaic, Classical, and Hellenistic date were also excavated near the outer boundaries of the town to the north and east of the acropolis.

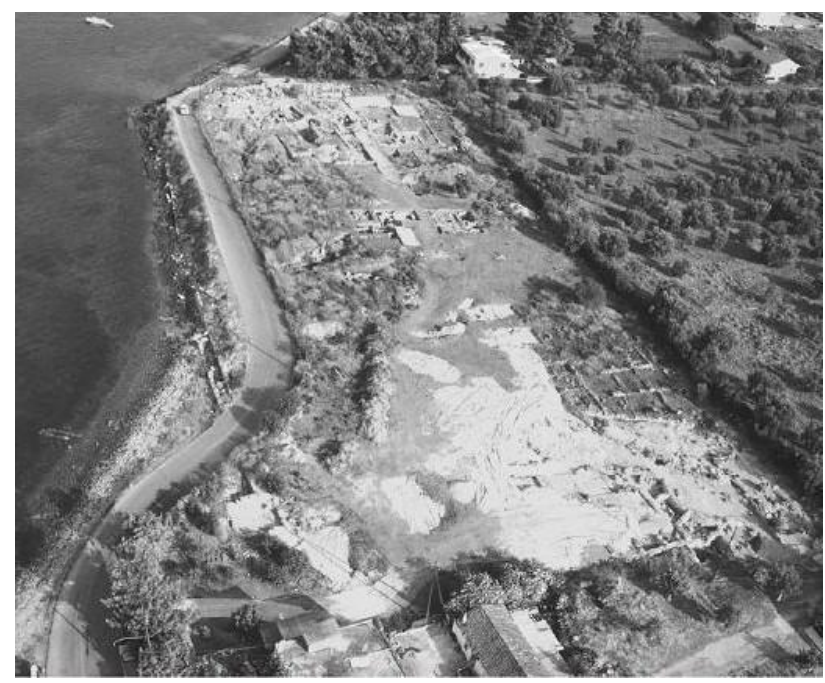

Figure 2. Aerial view (southeast aspect) of the site of Halai (C) J. Coleman

Halai, in the ancient Greek terminology «A $\lambda \dot{\varepsilon} \varsigma »$, means "salty"

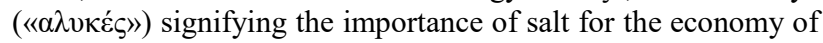
the city (Coleman et al., 1992, Kakavas, 2015). The rise, however, of the sea level has destroyed the remains of the ancient salt marshes today. The site of Halai is reported by Strabo (9.4.2), Pausanias (9.24.5) and Plutarch (Sulla 26), while urban activities are well certified by the many inscriptions found on and around the acropolis, dating from the Archaic to the Late RomanPaleochristian era.

The sea level when the Neolithic settlers arrived in $6000 \mathrm{BC}$ in Halai is estimated to be about $20 \mathrm{~m}$. lower than today. The rise of the sea level is due to the global warming since the last ice age (Last Glacial Maximum), along with the tectonic movements, isostatic sea level changes and eustatism. Therefore, in the past the hill where the acropolis was founded was about $2 \mathrm{~km}$ away from the seashore. Around $5300 \mathrm{BC}$, the Neolithic settlement was abandoned as the sea level had climbed another $10 \mathrm{~m}$. and the acropolis was only $800 \mathrm{~m}$ away from the seashore. The loss of arable land due to the rise in sea level may have been the main factor in the abandonment of the Neolithic settlement. During the Archaic period the level was estimated to be approximately $5 \mathrm{~m}$. lower than today and the seaside lasted $100 \mathrm{~m}$. from the acropolis. Since then the sea level has continued to rise. Today the sea embraces the citadel's fortifications and as a result the ancient 
ruins are detected at its bottom, in front of the acropolis, at a depth of at least $2 \mathrm{~m}$. from the surface. The geological rift of Atalanti $\rightarrow$ Larymna is one of the most active fissures in the area of East Locrida, where Halai is situated. It has an area of about $30 \mathrm{~km}$. and passes near the current cities of Atalanti, Kyparissi, Tragana, Martino and Larymna.

The ancient geographical area of Opountian Locris also includes the major harbor-towns of Larymna, Opous, Livanates, Kynos, Arkitsa and Thronion. The antiquities situated in these ancient harbor-towns are now semi or in many cases fully submerged due to the ongoing sea-level fluctuation.



Figure 3. Plan of the excavation segments in Acropolis of Halai. The underwater fortification is situated in Area G $\subset$ J. Coleman

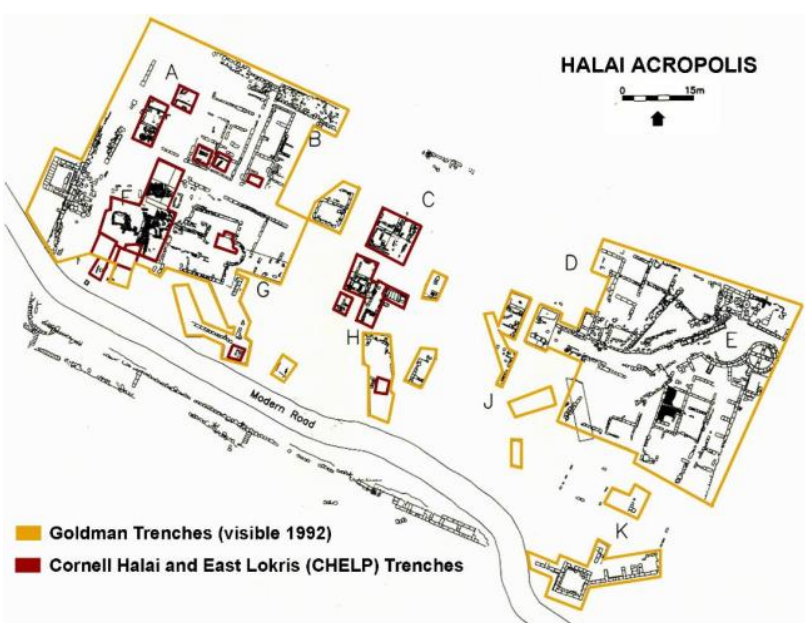

Figure 4. Plan of the H. Goldman Trenches \& Cornell Halai and East Locris Trenches (CHELP) (C) J. Coleman

\subsection{The Enhancement of Halai's Underwater Antiquities}

The site falls within the boundaries of the modern town of Theologos, a former fishing village which has become a popular destination spot during summer vacations. Yet, the rapid expansion of Theologos in recent years poses a considerable threat to the coastal antiquities, due to the major access road which passes over the Acropolis of Halai and as a result the site is divided into two parts. In addition with the road construction project, a significant part of the site is partial submerged in swallow waters due to the constant marine and climate changes.
As a result part of the Hellenistic fortification along with other cultural heritage assets of the acropolis are in danger due to the constant sea-level fluctuation.

The present research idea aims to enrich the protection and enhancement of Halai underwater heritage using digital tools such as AR. The Augmented Reality in this case will contribute to the creation of an immersive coastal path that will help both scholars, citizens and future visitors to reinforce the strong historic connection between the ancient civilizations of the place with the sea. Through an immersive coastal or/and floating visit to the swallow waters of the Halai's natural port, the users will gain a diverse information about the part of the archaeological site that is now invisible to non-divers. The means of the aforementioned floating visit could have been bottom-glass boats, or even simple boats.

Thus, this process is presented here as a primary station of a flexible maritime network, which in the future may include the major harbor-towns of Larymna, Halais, Opous, Livanates, Kynos, Arkitsa, Thronion, as well as the nearby coastal archaeological sites which fall within the geographic area of our research study.

\section{THE PROPOSED SYSTEM ARCHITECTURE}

Regarding the advancements in the Information and Communication Technologies (ICT), the proposed system architecture allows an easy and effective interaction with the real-world environment that can be applied to (semi) submerged antiquities, within the concept of the upcoming evolution of the Fifth Generation (5G) wireless communication networks and the developments in the field of Cloud Computing (CC), Mobile Edge Computing (MEC) or Fog infrastructures, sensors and IoT devices and services (Siountri et al., 2018).

The proposed system architecture combines AR technology, the use of the proposed Smart Cultural Heritage as a Service (SCHaaS) delivery model (Siountri, et al., 2018) as well as cloud and wireless communication infrastructures, in order to provide users and researchers information and data associated to a monument or archaeological interest place. More specifically, it can be used by residents or visitors of an area that are not aware of the "hidden" underwater antiquities or tourists that enjoy services like boat excursions along the coast etc. The users can be offered "dry experiences" that help them realize the cultural wealth near them or underneath them and make them also realize the connection between places with the same historical links, (e.g. the fortified city of Halai that half of it is visible and half of it is under water). Additionally, due to the proposed systems functionality this important information is associated with the geolocation data, providing real time information, while at the same time preserves the data for future study in a cloud environment.

The Smart Cultural Heritage as a Service (SCHaaS) model presented in Figure 5 is applied. It combines Software as a Service (SaaS), Platform as a Service (PaaS) and Infrastructure as a Service (IaaS) functionalities, to provide a fully virtualized environment for services implementation, deployment, maintenance and usage.

Specifically, IaaS provides the appropriate infrastructure for offering PaaS, since it lets the user to create a virtualized infrastructure consisted of several Virtual Machines (VMs) or platforms. Thus, VMs created using IaaS are provided as PaaS to 
software developers along with the specific usage rights. Consequently, PaaS provides the appropriate components for offering SaaS, since the applications created and deployed using PaaS, can be offered as SaaS to users.

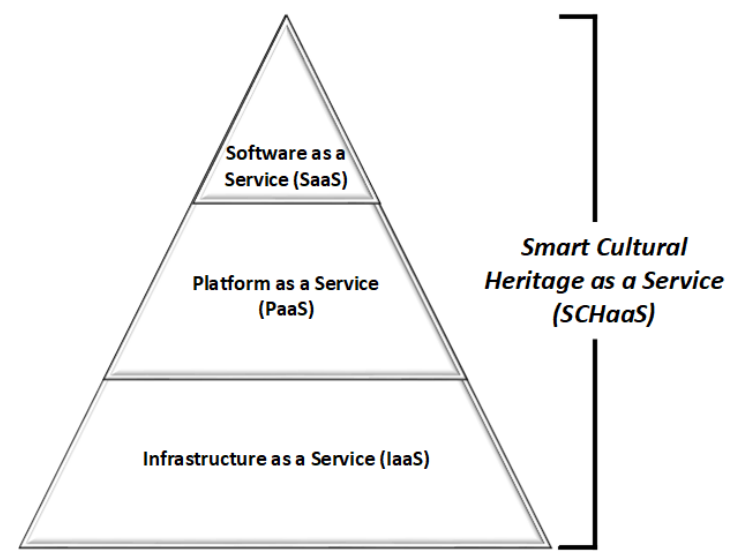

Figure 5. The Smart Cultural Heritage as a Service (SCHaaS) model

Figure 6 presents the proposed system architecture that has been developed using simulation software. Specifically, a trace file indicating the map of the place of Halai has been created using the Open Street Map software (Open Street Map - OSM, 2018). Then, the trace file has been used as input in the Simulator of Urban Mobility (SUMO) allowing the transfer of the real map to the considered simulation environment (Behrisch et al., 2011). Furthermore, a network topology is being built upon the map, using the Network Simulator 3 (Network Simulator 3 - NS3, 2018). It includes a Cloud and a Fog infrastructure.

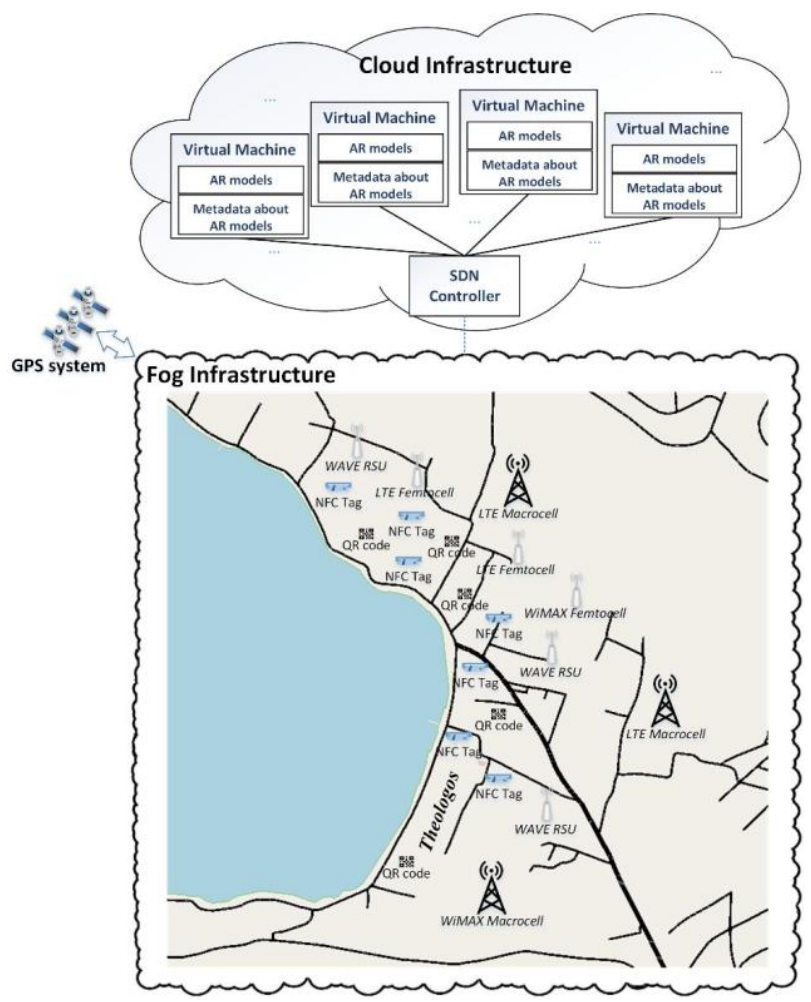

Figure 6 . The proposed system architecture

The Cloud infrastructure includes a set of virtual machines (VMs), while each VM hosts AR digital content about the archaeological findings. Accordingly, the Fog infrastructure consists of LTE Macrocell/Femtocell e-NodeBs (1609.3-2016, 2016), WiMAX Macrocell/ Femtocell Base Stations (802.16q2015, 2015) and 802.11p WAVE Road Side Units (RSUs) (1609.3-2016, 2016), providing access to the Cloud resources. Moreover, Near Field Communication (NFC) tags and Quick Response (QR) codes have been installed to specific positions of the Fog infrastructure (Vazquez-Briseno et al., 2012). Finally, a Software Defined Network (SDN) controller provides centralized control of the entire system (Nunes et al., 2014).

The sequence diagram of Figure 7 presents the system functionality. As the user moves inside the archaeological site of Halai or the coastal zone, his position is monitored using GPS equipment. The user interacts with the Fog infrastructure and retrieves AR content. If the requested AR data already exists to the Fog, they are immediately provided to the user. On the contrary, the Fog interacts with the Cloud infrastructure through the SDN controller, retrieves the requested AR models and, finally, transmits them to the user. In this case, the Fog caches the aforementioned AR models, in order to immediately transmit them to future users.

Additionally, the user can scan NFC tags and/or QR codes installed on the land using his device, to request AR content. Indicatively, visitors of the archaeological site of Halai can get notifications about the coastal antiquities or a passenger can be informed about the historical importance of his location from the signs that are placed by the road.

\section{DISCUSSION AND FUTURE WORK}

This research idea is still in progress, including the conclusion of the case study of Halai. This is a pilot study set up to explore the maritime network of the harbor-towns of Larymna, Opous, Livanates, Kynos, Arkitsa, Thronion, as well as the nearby coastal archaeological sites, which fall within the geographic area of Halai. These geographical aforementioned areas consist a part of our research projects, within the concept of "Smart Cultural Heritage as a Service (SCHaaS)", and the potential of the "Smart Tourism as a Service (STaaS)" research study, regarding the services that can be offered to the visitors of a place.

The discipline of maritime and underwater archaeology is a dynamic one: theory and practice are continually changing (Oxley, 2001). In addition to this fact, the available technologies (digital transformation) and the environment (climate change) is in a continuous transition, affecting the progress of the research in this field. These coastal archaeological places have a complex interaction with human through the years. They form a succinct outline of geohistory of the Atalantis Bay. The understanding, and yet the modeling of these maritime cultural systems still remains a challenging research work.

\section{CONCLUDING REMARKS}

In this paper, a multidisciplinary research concerning both innovative Underwater Cultural Heritage (UCH) management and the use of technology for the digitization, representation, documentation, and communication of cultural heritage knowledge has been analysed. AR technology can offer a gateway concept between the real world and the virtual world, rich in new content and services that can be applied to the "Smart Cultural Heritage as a Service (SCHaaS)" and "Smart Tourism as a Service (STaaS)" models. 


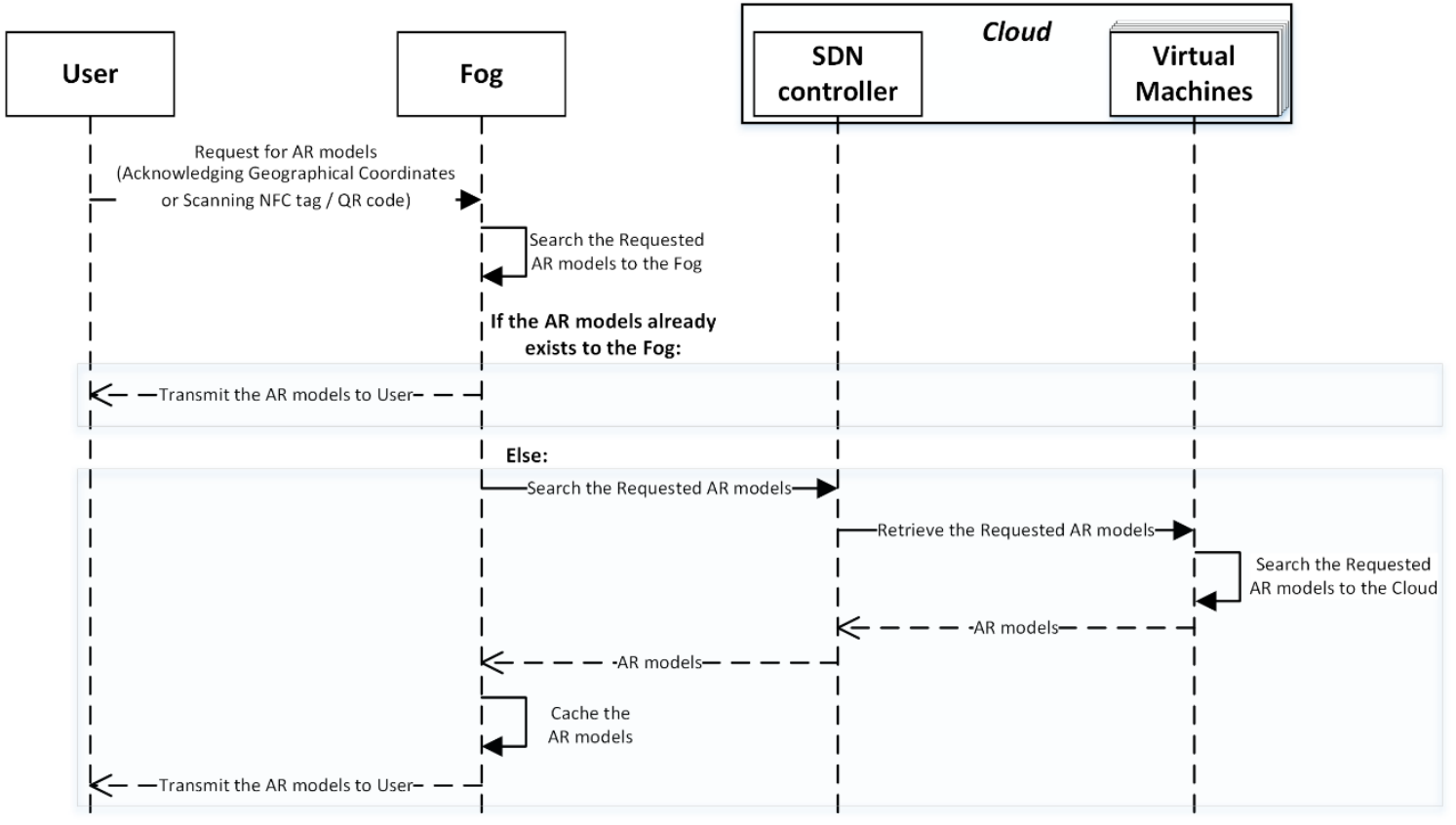

Figure 7. The sequence diagram indicating the functionality of the proposed system

The advances in the communication field, the up-coming $5 \mathrm{G}$ and cloud technologies will make the idea fully applicable to users, contributing to the enhancement of the coastal and the underwater archaeological findings. Moreover, the climate change may lead more and more antiquities covered by water the following years. In case there is no way to avoid these phenomena, our society must work on the idea of preserving "the memory" and "the knowledge" of the "hidden" past and pass it to the next generations.

\section{ACKNOWLEDGEMENTS}

The publication of this paper has been partly supported by the University of Piraeus Research Center (UPRC). The authors would like to thank Prof. John Coleman and Dr. George Kakavas for the supportive distribution of their rich photographic material as well as for the various plans of the excavation segments from the acropolis of Halai.

\section{REFERENCES}

Antonczak, L., Papetti, C, 2017. "Towards a Mobile Enhancement of Glocal Heritage? Developing user experiences in relation to mobile technologies, geo-localisation and culture", in the Thirteenth International Conference on Wireless and Mobile Communications (ICWMC) Proceedings, 2017, Nice, France. [URL: icwmc_2017_4_20_20070]

Behrisch, M., Bieker., L, Erdmann, J. \& Krajzewicz, D., 2011. Sumo-simulation of urban mobility: an overview, in: Proceedings of SIMUL 2011, The Third International Conference on Advances in System Simulation, ThinkMind. SIMUL 2011, 23-28, Oct., 2011, Barcelona.

Bruno F., Lagudi, A., Barbieri, L., Muzzupappa, M., Ritacco, G., Cozza, A., Cozza, M., Peluso, R., Lupia, M., Crio, G., 2016. Virtual and Augmented Reality Tools to Improve the Exploitation of Underwater Archaeological Sites by Diver and
Non-diver Tourists. In: Ioannides M. et al. (eds) Digital Heritage. Progress in Cultural Heritage: Documentation, Preservation, and Protection. EuroMed 2016. Lecture Notes in Computer Science, vol 10058. Springer, Cham.

Bruno, F., Barbieri, L., Lagudi, A. et al., 2018. Virtual Reality 22: 91. [doi.org/10.1007/s10055-017-0318-z]

Brusaporci, S., Ruggieri, G., Sicuranza, F., Maiezza, P., 2017. Augmented Reality for Historical Storytelling. The INCIPICT Project for the Reconstruction of Tangible and Intangible Image of L'Aquila Historical Centre. Proceedings 2017, 1, 1083.

Coleman, J., O'Neill, K., Pomeroy, M., Carr, K., Heafitz, A., 1992. Excavations at Halai, 1990-1991. Hesperia: The Journal of the American School of Classical Studies at Athens, 61(3), pp. 265-289.

Coleman J., Wren P., Quinn K., 1999. "Halai: the 1992-1994 Field Seasons", Hesperia, 68, pp. 286-338.

Coleman, J., Karimali, E., Karali, L., Fillios, M., Diffey, C., Vaiglova, P., Bogaard, A., Joos, J., Angeli, E., 2017. The Environment and Interactions of Neolithic Halai, in: Communities, Landscapes and Interaction in Neolithic Greece, Proceedings of the International Conference, Rethymno, 29-30 May 2015. Ed. Sarris, A., et al., International Monographs in Prehistory, Archaeological Series, 20, pp. 97-125.

Claudia, M. tom Dieck, Jung, T., 2018. A theoretical model of mobile augmented reality acceptance in urban heritage tourism, Current Issues in Tourism, 21:2, 154-174.

[doi: 10.1080/13683500.2015.1070801]

Goldman, H., 1940. The Acropolis of Halae. Hesperia: The Journal of the American School of Classical Studies at Athens, 9(4), pp. 381-514.

Hammady, R., Ma, M., \& Temple, N., 2016. Augmented reality and gamification in heritage museums. In Serious Games - 2nd 
Joint International Conference, JCSG 2016, Proceedings (Vol. 9894 LNCS, pp. 181-187). (Lecture Notes in Computer Science (including subseries Lecture Notes in Artificial Intelligence and Lecture Notes in Bioinformatics); Vol. 9894 LNCS). Springer Verlag. [https://doi.org/10.1007/978-3-319-45841-0_17]

Han, D., Jung, T., and Gibson, A., 2014. Dublin AR: Implementing Augmented Reality (AR) in Tourism, In Xiang, Z. and Tussyadiah, I. (eds), Information and Communication Technologies in Tourism, Springer International Publishing, Wien, New York, pp. 511-523. [doi: 10.1007/978-3-319-039732_37]

Haugstvedt, A. C., Krogstie, J., 2012. Mobile augmented reality for cultural heritage: A technology acceptance study. Paper presented at the IEEE, International Symposium on Mixed and Augmented Reality, 2012, Science and Technology Proceedings, Atlanta. [doi: 10.1109/ISMAR.2012.6402563]

Ijsselstein, W., Riva, G., 2003. Being there: the experience of presence in mediated environments. In: Being There: Concepts, effects and measurement of user presence in synthetic environments. G. Riva, F. Davide, W.A. Ijsselsteijn (Eds) Ios Press, Amsterdam, The Netherlands, pp. 1-14.

Kakavas, G., 2015. The city of Alles in the Early Christian and Mid-Byzantine period, in: Proceedings of the Scientific Conference: "Archaeological Sites and Monuments of the Municipality of Lokron Area. The present stage of Archaeological Research", Atalanti, 30/06-01/07 2012.

Kounavis, C. D., Kasimati, A. E., \& Zamani, E. D., 2012. Enhancing the tourism experience through mobile augmented reality: Challenges and prospects. International Journal of Engineering Business Management, 4(10), 1-6.

Leue M. C., Jung T., tom Dieck D., 2015. Google Glass Augmented Reality: Generic Learning Outcomes for Art Galleries. In I. Tussyadiah \& A. Inversini (Eds.), Information and Communication Technologies in Tourism, 2015, pp. 463-476. Vienna: Springer.

Liarokapis, F., Kouřil, P., Agrafiotis, P., Demesticha, S., Chmelík, J., Skarlatos, D., 2017. 3D Modelling and Mapping For Virtual Exploration of Underwater Archaeology Assets, Proceedings of the International Archives of the Photogrammetry, Remote Sensing and Spatial Information Sciences (ISPRS), XLII-2/W3, Napflio, Greece, 425-431, 2017. [doi.org/10.5194/isprs-archives-XLII-2-W3-425-2017]

Network Simulator 3 (NS3), 2018. [www.nsnam.org/]

Noh, Z., Sunar, M. and Pan, Z., 2009. A review on augmented reality for virtual heritage system, $4^{\text {th }}$ International Conference on E-Learning and Games: Learning by Playing. Game-based Education System Design and Development, pp. 50-61.

Nunes, B. A., Mendonca, M., Nguyen, X. N., Obraczka, K., \& Turletti, T., 2014. A survey of software-defined networking: Past, present, and future of programmable networks. IEEE Communications Surveys \& Tutorials, 16(3), 1617-1634.

Olsson, T., Kärkäinen, T., Lagerstam, E., \& Ventä-Olkkonen, L., 2012. User evaluation of mobile augmented reality scenarios. Journal of Ambient Intelligence and Smart Environments, 4(1), $29-47$.
O' Neill, K., Yielding, W., Near, J., Coleman, J., Wren, P., Quinn, K., 1999. Halai the 1992-1994 Field Seasons. Hesperia: The Journal of the American School of Classical Studies at Athens, 68(3), pp. 285-341.

Open Street Map, (OSM), 2018. [www.openstreetmap.org]

Oxley, I., 2001. Towards the integrated management of Scotland's cultural heritage: Examining historic shipwrecks as marine environmental resources, World Archaeology, 32:3, 413426. [doi.org/: 10.1080/00438240120048716]

Siountri K., Skondras E., Vergados D.D., 2018. A Delivery Model for Cultural Heritage Services in Smart Cities Environments. In: Ioannides M. et al. (eds) Digital Heritage. Progress in Cultural Heritage: Documentation, Preservation, and Protection. EuroMed 2018. Lecture Notes in Computer Science, vol. 11197. Springer, Cham.

Skarlatos, D., Agrafiotis, P., Balogh, T., Bruno, F., Castro, F., Davidde Petriaggi, B., Demesticha, D., Doulamis, A., Drap, P., Georgopoulos, A., Kikillos, F., Kyriakidis, P., Liarokapis, F., Poullis, C., Rizvic, S., 2016. Project iMARECULTURE: Advanced VR, iMmersive Serious Games and Augmented REality as Tools to Raise Awareness and Access to European Underwater CULTURal heritagE. In: Ioannides M. et al. (eds) Digital Heritage. Progress in Cultural Heritage: Documentation, Preservation, and Protection. EuroMed 2016. Lecture Notes in Computer Science, vol 10058. Springer, Cham.

Unesco, 2001. Convention on the protection of the underwater cultural heritage, 2 November 2001. [https://en.unesco.org/]

Vazquez-Briseno, M., Hirata, F. I., de Dios Sanchez-Lopez, J., Jimenez-Garcia, E., Navarro-Cota, C., \& Nieto-Hipolito, J. I., 2012. Using RFID/NFC and QR-code in mobile phones to link the physical and the digital world. In Interactive Multimedia. InTech.

Vecchio P., Mele F., De Paolis L.T., Epicoco I., Mancini M., Aloisio G., 2015. Cloud Computing and Augmented Reality for Cultural Heritage. In: De Paolis L., Mongelli A. (eds), Augmented and Virtual Reality. AVR 2015. Lecture Notes in Computer Science, vol 9254. Springer, Cham.

Yiannouli, E., 2016. A.Sho.Re. 2011-2015, SE Kephallenia in the Ionian Sea: Investigating the geoarchaeology of the coastal zone. In Photos-Jones, E., Bassiakos, Y., Filippaki, E., Hein, A., Karatasios, I. Kilikoglou, V. and E. Kouloumpi (eds) Proceedings of the $6^{\text {th }}$ Symposium of the Hellenic Society for Archaeometry, Athens 16-18 May 2013, The Acropolis Museum. British Archaeological Reports S2780. Oxford, Archaeopress, Chapter 26, 179-185.

802.16q-2015., 2015. Standard for air interface for broadband wireless access systems- amendment 3 multi-tier networks. Technical Specifications Book. IEEE.

1609.3-2016., 2016. Standard for wireless access in vehicular environments (wave) - networking services. Technical Specifications Book. IEEE.

TS36.300-V13.2.0., 2016. Evolved Universal Terrestrial Radio Access Network (E-UTRAN-Rel.13). Technical Specifications Book. 3GPP. 